\title{
Multi-objective optimization of selected non-traditional machining processes using NSGA-II
}

\author{
Dinesh Singh $^{a^{*}}$ and Rajkamal Shukla ${ }^{a}$
}

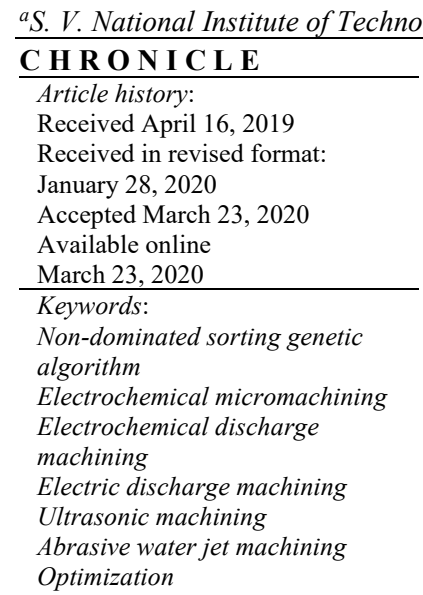
\begin{abstract}
A B S T R A C T
A non-dominated sorting genetic algorithm (NSGA-II) is applied to obtain Pareto optimal solutions in widely used advanced machining processes, i.e., electric discharge machining, electrochemical micromachining, ultrasonic machining, abrasive water jet machining. The solutions obtained using the proposed method is in the form of the Pareto-optimal front, thus, any solution is acceptable and can be utilized to obtain optimum performance of the considered processes. The obtained results using NSGA-II show good agreement with the results of previous researchers. Implementation of the proposed method shows benefits to the process engineer of the industries as they can select alternative parameters based on the requirement.
\end{abstract}

(C) 2020 by the authors; licensee Growing Science, Canada.

\section{Introduction}

Non-traditional machining (NTM) processes are extensively used in automotive and nuclear industries for machining defined, irregular and complex shapes in difficult to hard materials. Machining processes such as electric discharge machining (EDM), electrochemical micromachining (EMM), abrasive water jet machining (AWJM), ultrasonic machining (USM) has different process parameters that are of utmost significance to enhance the performance parameter of these machining processes. Indecorously selected process parameters may result in overheating of the workpiece, short-circuit, uneven surface integrity. Therefore, definite and systematic mathematical approaches are required to obtain the optimum parameter setting for enhancing the performance of the advanced machining processes. Nondominated sorting genetic algorithm (NSGA-II) has unique characteristics compared to other evolutionary optimization algorithm. Unlike other optimization techniques, NSGA-II provides alternative solutions for each objective without being dominated or biased towards another solution present in the domain space (Yusoff et al., 2011). The control parameters of the algorithm can be easily tuned by performing certain trial runs for the problem of optimization. These factors and applications of NSGA-II attract researchers to demonstrate its effectiveness in the field of optimization. In this paper, an attempt is made to apply NSGA-II to four advanced machining processes such as EDM, EMM, USM and AWJM that have a wide variety of applications in modern industries to obtain alternative solutions known as Pareto-optimal solutions. The performance of the proposed method is not compared directly with the results of the previous researchers. As the previous researchers have

* Corresponding author.

E-mail address: dineshsinghmed@gmail.com (D. Singh)

C 2020 by the authors; licensee Growing Science, Canada. doi: $10.5267 /$ j.dsl.2020.3.003 
attempted single and weighted based optimization to obtain optimum solution for the considered machining processes. It is not fair enough to compare these solutions with alternative solutions of NSGA-II. However, the solution obtained using the proposed method has a wide range of domain solutions as compared to single solution obtained by previous researchers. Furthermore, the solutions are not obtained by giving different weights to the objectives thus the solutions are not biased towards any considered objectives.

\section{Literature survey}

Several researchers have proposed optimization techniques to obtain the best conditions of the process parameters for various machining processes (Acharya et al., 2013; Mandal et al., 2007; Gao et al., 2013). Keskin et al. (2005) have conducted an experimental investigation to determine the influence of machining parameters (i.e., spark timing, pulse time, and power) on surface roughness $(R a)$ for EDM process. Bharti et al. (2012) have conducted an experimental investigation on EDM to acquire the set of solutions for the mathematical model obtained using the artificial neural network (ANN). Rajurkar et al. (2013) have reviewed electrochemical machining (ECM) and EDM processes and shows that both the machining processes offer a better alternative or sometimes the only alternative in generating precise 3-D complex geometry for difficult-to machine materials. Muthuramalingam and Mohan (2014) have studied the influence of EDM electrical parameters (i.e., pulse shape and discharge energy) on performance measures (i.e., $M R R, R a$ and electrode wear rate). Subramanian and Thiagarajan (2014) has conducted an experiment on the EDM process and used analysis of variance (ANOVA) to obtain the significant process parameters on the considered performance parameters (i.e. $M R R$, electrode wear ratio $(E W R)$ and $R a)$. Teimouri and Baseri (2014) conducted experiments on EDM using a rotary tool for better flushing of the wreckage to improve the performance parameter (i.e., $M R R$ and $R a$ ) and developed adaptive neuro-fuzzy inference system models to optimize the process parameters using the continuous ant colony optimization (CACO) technique. Talla et al. (2015) have attempted fabrication of machine aluminium/alumina MMC using EDM by adding the aluminium powder in kerosene dielectric to improve the performance and the results obtained shows an increase in $M R R$ and decrease in surface roughness $(R a)$ when compared with the conventional EDM process. Dewangan et al. (2015) have conducted an experimental investigation to determine the influence of the machining parameters on surface integrity of EDM process. Asokan et al. (2008) established a regression model to determine the optimal machining parameters in ECM process and used ANOVA to determine the significant parameters that affects performance parameters (i.e., $M R R$ and $R a$ ). Parametric optimization of machining processes such ECM, electrochemical discharge machining (ECDM) and EMM using artificial bee colony (ABC) was attempted considering both the single and multi-objective optimization problems (Samanta and Chakroborty, 2011). Senthilkumar et al. (2011) studied the influence of ECM process parameters on the responses such as $M R R$ and $R a$ for the LM25 Al/10\% SiC composites and optimized these process parameters using response surface methodology (RSM). Kumar and Khamba (2008) have conducted experimentation on USM process for pure titanium and determine the influence of process parameters on the machining characteristics such as tool wear rate and $R a$. Singh and Gianender (2012) have summarized the applications and the progress of materials such as glass, titanium or ceramics in machining using USM process. Kumar (2013) have attempted the statistical analysis of the USM process parameters using the design of experiment (DOE) and the results obtained were validated. Bansal and Goyal (2013) have investigated the effect of different input materials using ANOVA on $M R R$ and $R a$ in Chemical-assisted Ultrasonic Machining (CUSM) process. Chakravorty et al. (2013) have presented four simple methods to analyse the past experimental data for USM process and the relative performances of these methods are then compared with the results obtained by the past researcher. Popli and Singh (2013) have presented a review of USM process parameters for different materials and made a remark that machining of material like super alloys still needs a research because of their wide applications in various industries. Goswami and Chakraborty (2015) have attempted two optimization techniques, i.e. the gravitational search algorithm (GSA) and fireworks algorithm (FWA) for parametric optimization of USM process parameters and the results were equated with the other popular population-based algorithms which show that FWA provides the best optimal results for the 
considered USM process. Kuruc et al. (2015) have investigated the USM machining parameters during machining of polycrystalline cubic boron nitride (PCBN) and results show a proper method to manufacture a tool with low Ra. Wenjun et al. (2011) proposed numerical simulation for AWJM process parameters with respect to cutting depth and the simulation results show closeness with the experimental data which validated the correctness of the simulation. Yue et al. (2014) have conducted an experimental investigation to determine the influence of water pressure, jet feed speed, abrasive mass flow rate, surface speed, and nozzle tilted angle on the responses (i.e. $M R R$ and $R a$ ) and used sequential approximation optimization (SAO) method to determine the optimal values of the considered process parameters. Yuvaraj and Kumar (2014) have conducted an experimental investigation on AWJM cutting process for AA5083-H32 material and used ANOVA to obtain the significance of the factors (i.e. water jet pressure, traverse rate, abrasive flow rate, and standoff distance). Lozano Torrubia (2015) has done finite element analysis (FEA) combined with Monte Carlo methods for predicting the average shape of AWJM footprints using different feed speeds. Schwartzentruber and Papini (2015) have examined the parameters (i.e., standoff distance, dwell time and pressure) that affect target material damage during piercing operations in borosilicate glass using AWJM process and the effects of these parameters on three nozzles of different size were compared. Srinivas and Deb (1994) have studied the non-dominated sorting in genetic algorithm along with a niche and speciation methods to find multiple Pareto optimal points simultaneously. Konak et al. (2006) have studied the various variants of the multi-objective genetic algorithm (MOGA) for solving complex problems whose objectives are conflicting in nature. Yusoff et al. (2011) have reviewed several optimization techniques with its applications in optimizing the parameters of the various machining processes. Jensen (2003) has presented an efficient algorithm for non-dominated sorting which can speed up the processing time of some multi-objective evolutionary algorithm (MOEA) and demonstrated to validate the improved version of the algorithm is indeed much faster than the previous MOEAs. Marler and Arora (2004) have reviewed multi-objective optimization methods for the continuous non-linear problem and categorized these methods.

The previous researchers have obtained the optimum solution considering both single and multiobjective optimization problems considering several techniques, but the solution obtained is either suboptimum or near to the optimum solution. Furthermore, Taguchi approach has been attempted by several researchers in predicting the optimum setting of the process parameters in different machining processes. In the next section, the theoretical formulation detail of NSGA-II is reported.

\section{Non-dominated sorting genetic algorithm}

Deb et al. (2002) proposed an NSGA-II technique for multi-objective optimization problems. The NSGA-II is a variant of GA that uses the genetic operators (i.e. crossover and mutation) to obtain alternative solutions. The selection operator of NSGA-II works differently from traditional GA. A shared fitness is used in NSGA-II for selection criterion and its value is calculated based on the ranking of the solution and crowding distance that is briefly described below and reported in (Deb et al., 2002; Kuriakose \& Shunmugam, 2005). In NSGA-II, randomly an initial population (chromosomes) is generated. In order to obtain the non-domination level, the solution of each individual chromosome is compared with other chromosomes. If the selected chromosomes dominate all others chromosomes, then it is marked as dominated else non-dominated. The non-dominated sorting is used to classify the entire population of chromosomes into the set of different fronts of non-dominated solutions. Each solution or chromosomes are allocated a rank that is equivalent to its non-domination level. The subpopulation with rank 1 is the set of solutions in the first front, assigned a dummy fitness $F_{1}$ to this front set. The Euclidean distance $\left(d_{i j}\right)$ of each chromosome present in the first front set with respect to all other chromosomes of the same front set is calculated using Eq. (1).

$$
d_{i j}=\sqrt{\sum_{x=1}^{n v a r}\left(\frac{x_{d}^{(i)}-x_{d}^{(j)}}{x_{d}^{\max }-x_{d}^{\min }}\right)^{2}}
$$


where, $x_{d}$ is the value of the $d^{\text {th }}$ decision variable, nvar is the number of variables and $i$ and $j$ are chromosomes numbers. The sharing function value of all the chromosomes within the first front set are computed using Eq. (2).

$$
\operatorname{sh}\left(d_{i j}\right)=\left\{\begin{array}{lr}
1-\left(\frac{d_{i j}}{\sigma_{\text {share }}}\right)^{2}, & \text { if } d_{i j}<\sigma_{\text {share }} \\
0, & \text { otherwise }
\end{array}\right.
$$

where, $\sigma_{\text {share }}$ is the maximum distance between two chromosomes. A niche count $\left(n c_{i}\right)$ is the value that provides an evaluation of crowding near a chromosome is calculated using Eq. (3).

$$
n c_{i}=\sum_{j=1}^{N} \operatorname{sh}\left(d_{i j}\right)
$$

where, $N$ is total population. Now, the shared fitness values $(F)$ of chromosomes are obtained by dividing the dummy fitness values with niche count, which is given in Eq. (4).

$$
F=\frac{F_{1}}{n c_{i}}
$$

After calculating the shared fitness, a small value is deducted from the shared fitness to assign dummy fitness $\left(F_{2}\right)$ to the subsequent front with rank 2 and the steps are repeated (Deb et al., 2002; Kuriakose and Shunmugam, 2005). This procedure is continued till all the values of the shared fitness are calculated. Based on the shared fitness value chromosomes are selected depending on the values obtained for cumulative probability. The genetic operators are applied to these selected chromosomes for the calculation of the objective function values. It is revealed from the literature that the use of metaheuristic technique, i.e., NSGA-II is adopted by different researchers due to its capability of solving complex problems of engineering efficiently. The application domain of NSGA-II is found in the field of structure green building designing (Wang et al., 2005), industrial crude oil distillation (Inamdar et al., 2004), job shop scheduling (Pashupathy et al., 2006), path finding in network (Rajabi-Bahaabadi et al., 2015), power planning (Ramesh et al., 2012), pulsed tube refrigeration system (Rout et al., 2014), system reliability problems (Taboada et al., 2007), heat exchanger (Wong et al., 2016), energy conservation systems (Yang et al., 2016). These applications of NSGA-II prove its applicability and effectiveness over the different problems.

In the next section, demonstration of NSGA is reported to see the effectiveness of the considered optimization technique on different machining processes. The results obtained are compared with the results of previous researcher's.

\section{Illustrative examples}

The considered NSGA-II algorithm is attempted to the four NTM processes such as EDM, EMM, USM and AWJM to obtain the set of alternative non-dominated solutions. These solutions are not biased towards the domain of the process parameters as no weight is given to the objectives considered in the illustrative examples of the machining processes.

\subsection{Example 1: EDM process}

Tzeng and Chen (2013) developed an EDM setup to study the effect of process parameters with respect to performance parameters and conducted experiments on JIS SKD 61 steel workpiece using a copper (density $8.9 \mathrm{~g} / \mathrm{cm}^{3}$ ) electrode tool. They kept the cutting time as 20 minutes for each set of the workpiece. Tzeng and Chen (2013) considered discharge current $(I)$, gap voltage $(V)$, pulse on-time $\left(t_{o n}\right)$, and pulse off-time $\left(t_{o f f}\right)$ as process parameters for the experimentation. They considered these factors based on engineers' experience and a reference of the handbook from the machine manufacturer. They developed a mathematical predictive regression model for the experiments conducted by them. In this paper, the same model is considered to apply NSGA-II to get the alternative optimum set of results. The bounds of the parameters are given in Table 1 . The performance parameters considered are material removal rate $(M R R)$, roughness average $(R a)$ and a relative electrode wear ratio $(R E W R)$. 
Table 1

Process factors and their bounds for EDM (Tzeng and Chen, 2013)

\begin{tabular}{lcccc}
\hline \multirow{2}{*}{ Parameter } & Discharge current (A) & Gap voltage $(\mathrm{V})$ & Pulse on-time $(\mu \mathrm{s})$ & \multicolumn{2}{c}{ Pulse off-time $(\mu \mathrm{s})$} \\
\cline { 2 - 5 } & $x_{1}$ & $x_{2}$ & $x_{3}$ & $x_{4}$ \\
\hline Lower bound & 7.5 & 45 & 50 & 40 \\
Upper bound & 12.5 & 55 & 150 & 60 \\
\hline
\end{tabular}

The mathematical predictive regression models for performance parameters $M R R, R a$ and $R E W R$ obtained by Tzeng and Chen (2013) are given in the Eq. (5) - (7) respectively.

$$
\begin{aligned}
& M R R=-253.15+39.7 x_{1}+4.277 x_{2}+1.569 x_{3}-1.375 x_{4}-0.0059 x_{3}^{2}-0.536 x_{1} x_{2} \\
& R a=31.547-0.618 x_{1}-0.438 x_{2}+0.059 x_{3}-0.59 x_{4}+0.019 x_{1} x_{4}+0.0075 x_{2} x_{4} \\
& R E W R=196.564-24.19 x_{1}-3.135 x_{2}-1.781 x_{3}+0.153 x_{4}+0.093 x_{1}^{2}+0.001491 x_{3}^{2}+0.005265 x_{4}^{2} \\
& \quad+0.464 x_{1} x_{2}+0.158 x_{1} x_{3}+0.025 x_{1} x_{4}+0.029 x_{2} x_{3}-0.017 x_{2} x_{4}-0.003385 x_{1} x_{2} x_{3}
\end{aligned}
$$

\subsubsection{Demonstration steps of NSGA-II}

In this section, the considered EDM problem is taken to demonstrate the application of NSGA-II. The objective 1 and objective 2 considered are given in Eq. (5) and (6) respectively. A single objective optimization is terminated upon attaining a single optimal solution. However, the NSGA-II provides a set of alternative solutions rather than the single solution. Suitability of the solutions be governed by some factors, including the problem environment and user choice, and hence obtaining the solution set of the optimal process variable is desirable. In the EDM process, the two objectives considered are $M R R$ and $R a$. The NSGA-II is applied to the EDM problem to measure the effectiveness of the algorithm and to get a set of alternative solutions, which will serve the purpose of getting optimal solutions. Table 2 shows the demonstration results of NSGA-II for EDM process considering Obj.1 and $O b j .2$ as $M R R$ and $R a$ respectively. In the demonstration phase, the third objective $R E W R$ is not taken into consideration. The steps of NSGA-II are described below.

The population size $(\mathrm{N})$ of the chromosomes considered is 20 . The random population of chromosomes is generated which consist of a set of binary numbers. Let the first chromosome is " 1001111000111011 ". The objective function values obtained for the first chromosome are 127.3210 and 8.9540 for MRR and $R a$ respectively and the decision variables (i.e. $x_{1}, x_{2}, x_{3}$ and $x_{4}$ ) values obtained are 12.5000, 54.3300, 96.6660 and 58.6700 respectively. The objective function values of the first chromosome are equated with objective function values of second chromosomes. The value of objective function 1 for first chromosomes (i.e. 127.3210) is less than the value of objective function 1 for the second chromosomes (i.e. 128.6670) and also the value of objective function 2 for first chromosomes (i.e. 8.9540) is less than the value of objective function 2 for the second chromosomes (i.e. 9.8340), hence both the solutions are non-dominating solutions. The evaluation is continued for all other chromosomes, and if it is found non-dominated till the end of sorting process then it is marked as rank 1 . This procedure of ranking is repeated for all other chromosomes present in the population. The ranking process emphasizes the best solution and increases the chances of finding the better solutions. The chromosomes with rank 1 are the set of solution of front 1 for a non-dominated solution and the chromosomes at rank 1 obtained are $1,2,3,6,9,14,16$ and 18. The distances of the first chromosome from all other chromosomes present in the front 1 are calculated using Eq. (1) and the values obtained are 0, 0.2496, 0.2579, 0.7380, 0.0499, $0.3536,0.2745$ and 0.6073 for chromosomes $1,2,3,6,9,14,16$ and 18 respectively. With these values, the sharing function values, i.e. $s h\left(d_{i j}\right)$ are determined for the first chromosome using Eq. (2). The suitable value of $\sigma_{\text {share }}$ is required to dispense the solution over the domain space. The value of $\sigma_{\text {share }}$ is assumed as 1.2 for the calculation of $s h\left(d_{i j}\right)$. Considering all the distance values of the first chromosome total sharing function value obtained is 7.1498 . The niche count value 8.3498 is obtained for the first chromosome as the summation of the sharing function value and $\sigma_{\text {share }}$ using Eq. (3). The dummy fitness value 50 is given to the first front chromosomes. The values of shared fitness for the first front are obtained using Eq. (4). After obtaining the values of shared fitness for the current front set of chromosomes, a small value, 0.3190 is deducted from the first chromosome to obtain the dummy fitness 
for the subsequent front set of non-dominated solution. The expected counts of all the chromosomes are obtained by taking the ratio of shared fitness value to the average shared fitness (3.0400) considering all the values of chromosomes as shown in Table 2(b). The probability values are obtained by taking the ratio of the expected count to the total number of chromosomes. Hence the values obtained for the first chromosomes for expected count and probability are 1.9700 and 0.0985 respectively. Then, the cumulative probability $(\mathrm{CP})$ and random number are generated for all the chromosomes present in the population and the chromosomes are selected with respect to the values obtained for cumulative probability and sorted random numbers as shown in Table 2 (c). The first chromosome (0011100011101001) after double point crossover at the site (7 to 14) becomes a new chromosome string (0011100111101101). Similarly, after mutation at site 8 and 14, the chromosome string (0011100111101101) becomes a new string as (0011100011101001). Table 2(c) shows the parameters (decision variable) and corresponding objective values. This process is repeated till the stopping criterion satisfied.

Table 2

Results of NSGA-II demonstration for $\mathrm{N}=20$

\begin{tabular}{|c|c|c|c|c|c|c|c|c|c|}
\hline \multicolumn{10}{|c|}{ (a) Initialization } \\
\hline \multirow{2}{*}{ S. No. } & \multirow{2}{*}{\multicolumn{2}{|c|}{ Chromosomes }} & \multicolumn{4}{|c|}{ Parameters } & \multirow{2}{*}{\multicolumn{2}{|c|}{ Obj. 1}} & \multirow{2}{*}{ Obj. 2} \\
\hline & & & $\mathrm{x}_{1}$ & \multirow{2}{*}{$\frac{\mathrm{x}_{2}}{543300}$} & $\mathrm{x}_{3}$ & \multirow{2}{*}{$\begin{array}{l}\mathrm{x}_{4} \\
586700\end{array}$} & & & \\
\hline 1 & \multicolumn{2}{|l|}{1001111000111011} & 12.5000 & & 96.6666 & & \multicolumn{2}{|r|}{127.3210} & 8.9540 \\
\hline 2 & \multicolumn{2}{|l|}{1101110010111110} & 11.1671 & 51.6700 & 123.3333 & 56.0000 & \multicolumn{2}{|r|}{128.6670} & 9.8340 \\
\hline 3 & \multicolumn{2}{|l|}{1100110010001100} & 9.1660 & 49.0000 & 96.6666 & 46.6700 & \multicolumn{2}{|r|}{111.9570} & 7.8678 \\
\hline 4 & \multicolumn{2}{|l|}{1111011010010110} & 7.5000 & 54.3300 & 110.0000 & 52.0000 & \multicolumn{2}{|r|}{88.2637} & 7.5240 \\
\hline 5 & 100010001110100 & & 9.8333 & 47.6700 & 96.6666 & 58.6700 & & 105.7400 & 7.6162 \\
\hline 6 & 000000100111110 & & 9.8333 & 55.0000 & 50.0000 & 49.3300 & & 78.4483 & 4.7904 \\
\hline 7 & 111110011101000 & & 8.5000 & 45.0000 & 143.3333 & 45.3300 & & 113.0890 & 10.9150 \\
\hline 8 & 111100101011000 & & 8.1660 & 53.6700 & 83.3333 & 45.3300 & & 93.1266 & 6.4449 \\
\hline 9 & 000101110010000 & & 10.5000 & 48.3300 & 123.3333 & 44.0000 & & 141.6660 & 9.9327 \\
\hline 10 & 100111101110110 & & 11.5000 & 49.0000 & 150.0000 & 44.0000 & & 153.0370 & 11.6520 \\
\hline 11 & 010010001000000 & & 7.8333 & 51.0000 & 130.0000 & 57.3300 & & 87.2550 & 8.6744 \\
\hline 12 & 100101101111101 & & 8.5000 & 48.3300 & 136.6666 & 40.0000 & & 120.0460 & 10.5470 \\
\hline 13 & 011010111111100 & & 7.5000 & 53.6700 & 136.6666 & 41.3300 & & 105.7900 & 9.6093 \\
\hline 14 & 001111010011000 & & 12.1670 & 51.0000 & 143.3333 & 44.0000 & & 158.5830 & 11.1880 \\
\hline 15 & 001110010111011 & & 8.1667 & 50.3300 & 110.0000 & 60.0000 & & 84.7166 & 7.5040 \\
\hline 16 & 010101111101111 & & 11.8330 & 45.0000 & 136.6666 & 50.6700 & & 158.2430 & 11.1860 \\
\hline 17 & 010000110110101 & & 8.5000 & 46.3300 & 96.6666 & 45.3300 & & 105.5770 & 8.0313 \\
\hline 18 & 110111001101101 & & 11.8330 & 50.3300 & 56.6666 & 54.6700 & & 107.4590 & 6.2056 \\
\hline 19 & 101101001100111 & & 9.8333 & 55.0000 & 150.0000 & 56.0000 & & 108.1820 & 10.7530 \\
\hline 20 & 100000001110011 & & 9.5000 & 50.3300 & 76.6666 & 60.0000 & & 86.0894 & 6.2333 \\
\hline (b) $\mathrm{So}$ & ing w.r.t rank & & & & & & & & \\
\hline Rank & $\begin{array}{c}\text { Chromosomes } \\
\text { w.r.t } \\
\text { Rank }\end{array}$ & Obj. 1 & Obj. 2 & $\begin{array}{l}\text { Niche } \\
\text { count }\end{array}$ & $\begin{array}{l}\text { Dummy } \\
\text { fitness }\end{array}$ & $\begin{array}{l}\text { Shared } \\
\text { fitness }\end{array}$ & $\begin{array}{l}\text { Expected } \\
\text { count }\end{array}$ & Probability & $\begin{array}{l}\text { Commutative } \\
\text { probability } \\
\text { (C.P) }\end{array}$ \\
\hline 1 & 1001111000111011 & 127.3210 & 8.9500 & 8.3498 & 50.0000 & 5.9880 & 1.9700 & 0.0985 & 0.0980 \\
\hline 1 & 1101110010111110 & 128.6670 & 9.8300 & 7.7700 & 50.0000 & 6.4310 & 2.1160 & 0.1057 & 0.2040 \\
\hline 1 & 1100110010001100 & 111.9570 & 7.8700 & 8.2200 & 50.0000 & 6.0850 & 2.0020 & 0.1001 & 0.3040 \\
\hline 1 & 0000001001111101 & 78.44830 & 4.7900 & 6.100 & 50.0000 & 8.1910 & 2.6950 & 0.1347 & 0.4390 \\
\hline 1 & 0001011100100001 & 141.6660 & 9.9300 & 8.2900 & 50.0000 & 6.0310 & 1.9840 & 0.0992 & 0.5380 \\
\hline 1 & 0011110100110001 & 158.5830 & 11.2000 & 7.3300 & 50.0000 & 6.8210 & 2.2440 & 0.1121 & 0.6510 \\
\hline 1 & 0101011111011110 & 158.2430 & 11.2000 & 7.6800 & 50.0000 & 6.5110 & 2.1420 & 0.1071 & 0.7580 \\
\hline 1 & 1101110011011011 & 107.4590 & 6.2100 & 6.8600 & 50.0000 & 7.2900 & 2.3980 & 0.1199 & 0.8780 \\
\hline 2 & 1000100011101000 & 105.7400 & 7.6200 & 8.1000 & 5.6690 & 0.7000 & 0.2300 & 0.0115 & 0.8890 \\
\hline 2 & 1111001010110000 & 93.1266 & 6.4400 & 7.2900 & 5.6690 & 0.7780 & 0.2560 & 0.0128 & 0.9020 \\
\hline 2 & 1001111011101100 & 153.0370 & 11.7000 & 7.1300 & 5.6690 & 0.7950 & 0.2620 & 0.0131 & 0.9150 \\
\hline 2 & 1001011011111011 & 120.0460 & 10.5000 & 8.0200 & 5.6690 & 0.7070 & 0.2320 & 0.0116 & 0.9270 \\
\hline 2 & 0110101111111001 & 105.7900 & 9.6100 & 7.8600 & 5.6690 & 0.7210 & 0.2370 & 0.0119 & 0.9380 \\
\hline 2 & 1000000011100111 & 86.0894 & 6.2300 & 7.6000 & 5.6690 & 0.7460 & 0.2450 & 0.0123 & 0.9510 \\
\hline 3 & 1111011010010110 & 88.2637 & 7.5200 & 1.2000 & 0.6680 & 0.5570 & 0.1830 & 0.0092 & 0.9600 \\
\hline 3 & 1111100111010000 & -113.0890 & 10.9000 & 1.2000 & 0.6680 & 0.5570 & 0.1830 & 0.0092 & 0.9690 \\
\hline 3 & 0011100101110110 & -84.7166 & 7.5000 & 1.2000 & 0.6680 & 0.5570 & 0.1830 & 0.0092 & 0.9780 \\
\hline 3 & 0100001101101011 & -105.5770 & 8.0300 & 1.2000 & 0.6680 & 0.5570 & 0.1830 & 0.0092 & 0.9870 \\
\hline 3 & 1011010011001111 & -108.1820 & 10.8000 & 1.2000 & 0.6680 & 0.5570 & 0.1830 & 0.0092 & 0.9960 \\
\hline 4 & 0100100010000001 & -87.2550 & 8.6700 & 1.2000 & 0.2590 & 0.2160 & 0.0710 & 0.0036 & 1.0000 \\
\hline
\end{tabular}




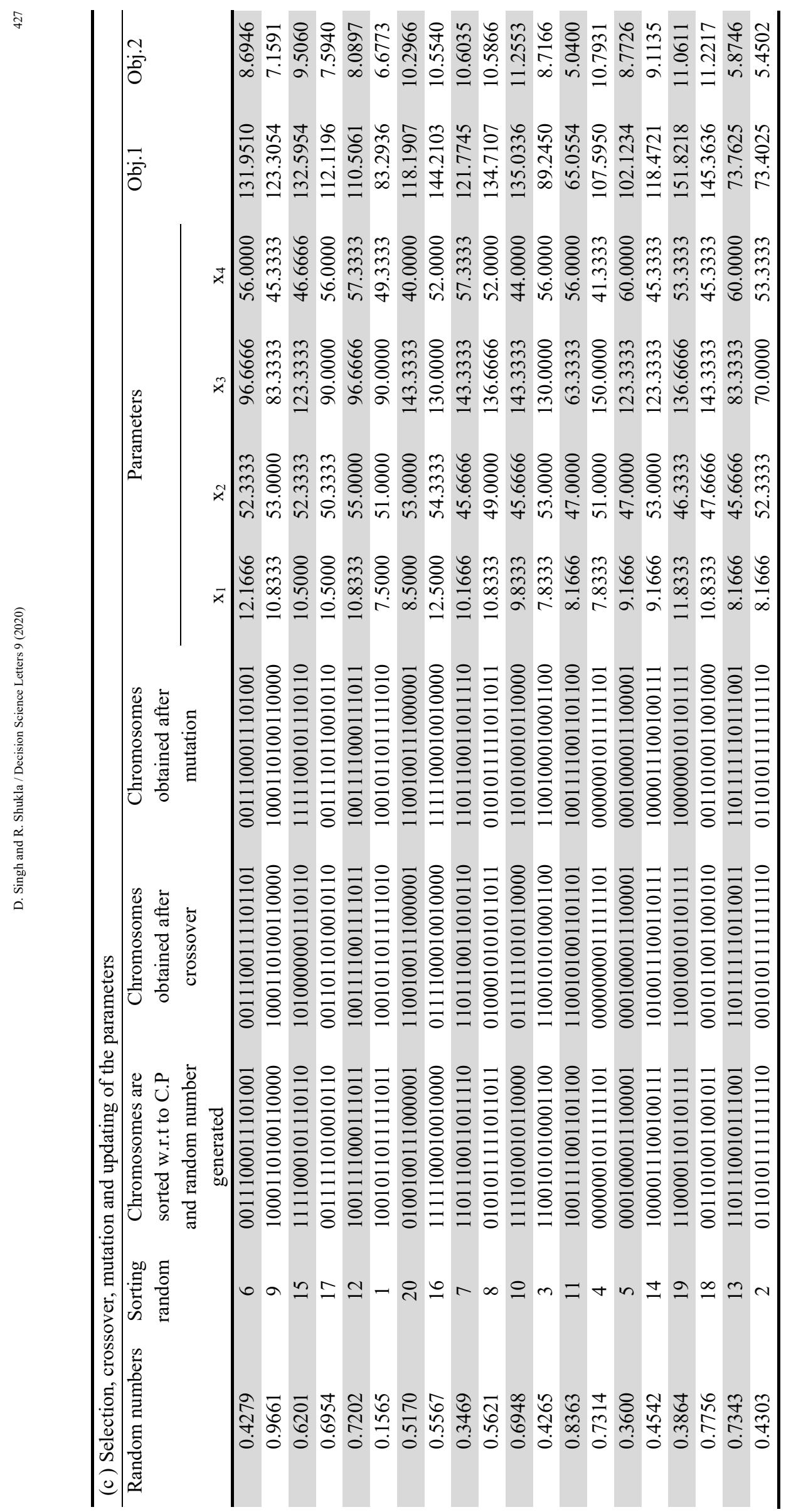




\subsubsection{Multi-objective optimization of EDM process}

In the considered example of the EDM process, the responses (MRR and $R a$ ) are optimized simultaneously. The Matlab code for NSGA-II is developed in MATLAB $7.12^{\circledR}$ with the following parameters for the better convergence of the considered optimization problem.

Maximum number of iteration $\quad 1000$

Population size 100

Crossover probability $\quad 0.5$

Mutation probability $\quad 0.3$

These control parameters are selected on the basis of the parametric analysis. The results obtained for the parametric analysis is reported in Appendix A. In this problem, the aim is to maximize the objective "MRR" and to minimize the objective " $R a$ " for EDM process. Since the objectives are differing in nature, modification of the first objective (i.e. $M R R$ ) is made to convert it into minimization (i.e., $M R R)$. The objectives are given in Eq. (8)

Obj.1 $=-M R R$

Obj.2 $=R a$

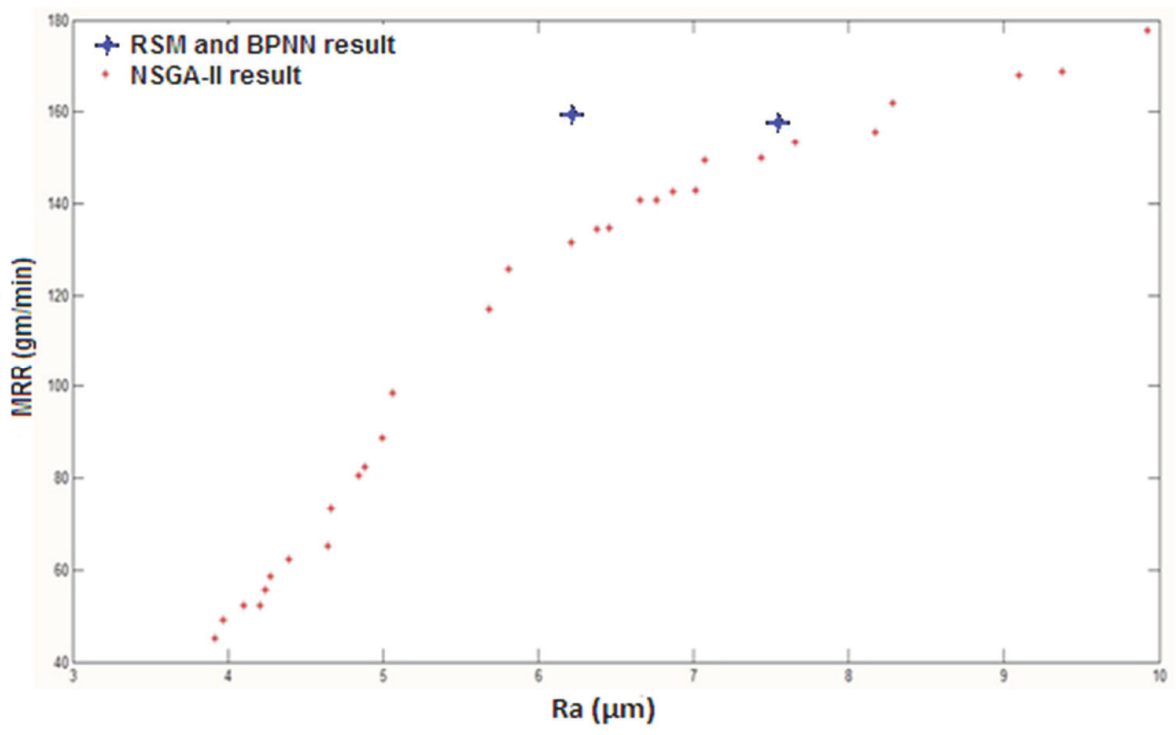

Fig. 1. Pareto optimal front and comparison of result for EDM process

Initially using control parameters of NSGA-II, The values of objective functions are obtained. For better convergence, 1000 iterations (maximum generation) and 100 population size are considered in this problem. Thirty non-dominated solutions are found at the end of the 1000 generations with computation time 256.3 seconds. The computer processor used is Dell-Intel Core-I3 fourth generation with 2GB RAM. The Pareto-optimal solution along with the performance parameters are reported in Table 3 and the Pareto-optimal front for all non-dominated solutions is shown in Fig. 1. The shape of the Pareto-optimal front is a consequence of the continuous nature of the considered optimization problem. The results reported in Table 3 clearly represent thirty non-dominated solutions and previous researcher's results of Tzeng and Chen (2013) for the considered EDM process. 
Table 3

Comparison of NSGA-II results for EDM process

\begin{tabular}{|c|c|c|c|c|c|c|c|}
\hline Algorithm & $\begin{array}{l}\text { Discharge current } \\
\text { (A) }\end{array}$ & $\begin{array}{c}\text { Gap } \\
\text { voltage } \\
(\mathrm{V})\end{array}$ & $\begin{array}{l}\text { Pulse on } \\
\text { time }(\mu \mathrm{s})\end{array}$ & $\begin{array}{c}\text { Pulse off } \\
\text { time } \\
(\mu \mathrm{s})\end{array}$ & $\begin{array}{l}\text { MRR } \\
(\mathrm{g} / \mathrm{min})\end{array}$ & $\begin{array}{c}\mathrm{Ra} \\
(\mu \mathrm{m})\end{array}$ & $\begin{array}{c}\text { REWR } \\
(\%)\end{array}$ \\
\hline RSM (Tzeng and chen, 2013) & 12.50 & 47.11 & 73.89 & 40 & 157.39 & 7.63 & 7.83 \\
\hline BPNN/GA Tzeng and chen, 2013) & 12.23 & 48.25 & 89.58 & 40.06 & 159.70 & 6.21 & 7.04 \\
\hline \multirow{30}{*}{ NSGA-II } & 9.0054 & 54.7654 & 51.9550 & 48.2502 & 73.4963 & 4.6662 & 10.1910 \\
\hline & 12.1383 & 46.9746 & 60.6549 & 41.1535 & 140.9037 & 6.7586 & 8.1265 \\
\hline & 7.9643 & 50.9531 & 51.5640 & 55.6012 & 52.2126 & 4.2068 & 8.4318 \\
\hline & 12.3485 & 45.5767 & 69.1593 & 44.1838 & 149.8923 & 7.4346 & 5.2854 \\
\hline & 12.0552 & 46.9453 & 55.7674 & 41.6813 & 134.7240 & 6.4558 & 9.3322 \\
\hline & 12.2507 & 46.8768 & 85.8749 & 40.1955 & 161.8440 & 8.2831 & 2.6958 \\
\hline & 10.2028 & 53.8661 & 52.5415 & 40.1760 & 98.6174 & 5.0636 & 13.2490 \\
\hline & 12.4511 & 45.6061 & 110.2151 & 40.2151 & 177.8132 & 9.9217 & 1.1391 \\
\hline & 10.3446 & 54.3842 & 50.6843 & 46.6667 & 88.7877 & 4.9975 & 14.1720 \\
\hline & 8.6486 & 53.4555 & 51.8573 & 40.6256 & 80.6651 & 4.8423 & 9.7627 \\
\hline & 12.3583 & 47.9130 & 101.8084 & 40.5279 & 167.8782 & 9.0988 & 1.0452 \\
\hline & 7.6369 & 54.5308 & 50.7820 & 54.8583 & 49.0793 & 3.9686 & 6.7829 \\
\hline & 7.7688 & 53.1329 & 50 & 52.9423 & 52.1758 & 4.0997 & 7.7575 \\
\hline & 12.1139 & 47.1994 & 54.7898 & 41.5249 & 134.3324 & 6.3773 & 9.9110 \\
\hline & 8.9956 & 54.3646 & 54.2033 & 43.3236 & 82.5070 & 4.8823 & 9.7935 \\
\hline & 12.4756 & 48.3333 & 77.6637 & 42.4633 & 153.5318 & 7.6542 & 5.9573 \\
\hline & 12.0552 & 46.5934 & 64.4673 & 41.7400 & 142.8907 & 7.0125 & 6.8040 \\
\hline & 8.0816 & 54.4135 & 52.1505 & 49.5797 & 62.3173 & 4.3908 & 7.7133 \\
\hline & 7.8715 & 50.5523 & 51.6618 & 59.8631 & 45.2725 & 3.9190 & 8.8022 \\
\hline & 12.2801 & 47.2581 & 62.7077 & 42.1310 & 142.6912 & 6.8641 & 8.1367 \\
\hline & 12.1579 & 47.5415 & 60.0684 & 40.1173 & 140.8401 & 6.6564 & 8.8210 \\
\hline & 12.0503 & 45.8016 & 82.8446 & 43.0694 & 155.580 & 8.1716 & 2.5535 \\
\hline & 7.8470 & 54.0714 & 51.1730 & 49.7556 & 58.6419 & 4.2736 & 7.4603 \\
\hline & 12.2947 & 46.8280 & 50.8798 & 43.3627 & 131.5718 & 6.2150 & 10.9090 \\
\hline & 12.4853 & 47.2385 & 65.6403 & 41.0362 & 149.5741 & 7.0753 & 7.4907 \\
\hline & 7.7199 & 53.9443 & 52.3460 & 51.6129 & 55.8325 & 4.2375 & 6.8336 \\
\hline & 12.4658 & 46.7986 & 103.7634 & 43.4604 & 168.7292 & 9.3735 & 0.5456 \\
\hline & 9.1667 & 53.2991 & 50.7820 & 55.3275 & 65.2374 & 4.6429 & 10.8320 \\
\hline & 11.3612 & 49.6334 & 50.3910 & 40 & 117.0057 & 5.6839 & 12.7820 \\
\hline & 12.1334 & 49.5455 & 50.1955 & 40.9580 & 125.8073 & 5.8058 & 13.9500 \\
\hline
\end{tabular}

Tzeng and Chen (2013) obtained the performance parameters for $M R R, R a$ and $R E W R$ as $\{157.39 \mathrm{~g} / \mathrm{min}$ $7.83 \mu \mathrm{m}$ and $7.63 \%\}$ and $\{159.70 \mathrm{~g} / \mathrm{min} 7.04 \mu \mathrm{m}$ and 6.21$\}$ using response surface methodology (RSM) and genetic algorithm (GA) respectively. The solutions obtained in the considered EDM process using NSGA-II are compared with results of Tzeng and Chen (2013) for the considered objectives. These non-dominated solutions obtained using NSGA-II is far better than those achieved in Tzeng and Chen (2013). The results obtained using NSGA-II are alternative solutions for the same problem considered by Tzeng and Chen (2013). So, it is feasible for the process engineer to select a suitable alternative as per the requirement. The whole range of input parameters is replicated in the results (Table 3) and no bias towards the lower or higher bound values are seen. This is the main advantage of using NSGA-II that allows the solutions from all fronts to co-exist. Since both the objectives are conflicting in nature, it is clearly observed in the solutions that as MRR values are increasing, the values of Ra decreases. 


\subsection{Example 2: EMM process}

This example of EMM is taken from Munda and Bhattacharya (2006) for parameter optimization. Munda and Bhattacharya (2006) developed an EMM setup where copper plates having $15 \times 10 \times 0.15$ $\mathrm{mm}^{3}$ dimension were utilized as workpiece material and a stainless steel wire of diameter $335 \mathrm{~mm}$ was used as a micro-tool. They have observed that for attaining the optimum performance of the considered EMM process, process parameters such as pulse on/off ratio, machining voltage, electrolyte concentration, voltage frequency and tool vibration frequency should be properly selected. In this paper, the same process parameters are considered for parameter optimization. The range of these process parameters is given in Table 4.

\section{Table 4}

Process factors and their bounds for EMM (Munda and Bhattacharya, 2006)

\begin{tabular}{lccc}
\hline & Symbols & Lower bound & Upper bound \\
\hline Pulse on/off ratio & $x_{1}$ & 0.5 & 2.5 \\
Machining voltage $(\mathrm{V})$ & $x_{2}$ & 2.5 & 4.5 \\
Electrolyte concentration $(\mathrm{g} / \mathrm{l})$ & $x_{3}$ & 10 & 30 \\
Voltage frequency $(\mathrm{Hz})$ & $x_{4}$ & 35 & 55 \\
Tool vibration frequency $(\mathrm{Hz})$ & $x_{5}$ & 100 & 300 \\
\hline
\end{tabular}

The performance parameters considered by Munda and Bhattacharya (2006) are material removal rate (MRR) and a radial overcut (ROC). The mathematical predictive regression models considered are same as given in Munda and Bhattacharya (2006) which is given in Eq. (9) and (10) respectively.

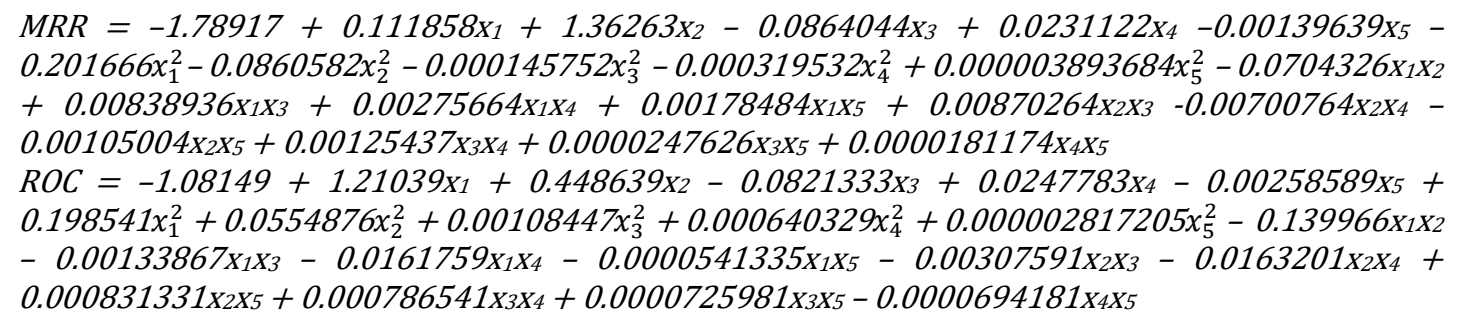

In the considered example of the EMM process, both the responses (MRR and ROC) are optimized simultaneously. In the considered example, the number of iterations is taken as 1500 (as the number of variables is increased by one only, i.e., 5) and other control parameters for EMM process are same as considered in the previous example of EDM process. The aim of the present work is to maximize the objective MRR and to minimize the objective ROC using Eq. (10) and (11) for EMM process. The objective functions are taken from Munda and Bhattacharya (2006). Since the objectives are differing in nature, modification of the first objective (MRR) is made as done in the EDM example to convert it into a minimization problem. The objectives are given in Eq. (11). Twelve solutions are obtained with computation time 769.63 seconds. The Pareto-optimal solutions and previous researcher result of ABC weight based multi-objective optimization attempted by Samanta and Chakraborty (2011) are reported in Table 5 for the considered EMM process. Fig. 2 shows the Pareto- optimal front and the previous researcher results obtained using $\mathrm{ABC}$ weighted based multi objective optimization for the considered problem.

$$
\begin{aligned}
& \text { Objective } 1=-(\text { MRR }) \\
& \text { Objective } 2=\text { ROC }
\end{aligned}
$$

The solution obtained in the considered EMM process using NSGA-II cannot be compared with the result of Munda and Bhattacharya (2006) as they had not attempted the problem of multi-objective optimization. Munda and Bhattacharya (2006) obtained results for the performance parameter MRR and ROC as $0.7034(\mathrm{~g} / \mathrm{min})$ and $20(\mu \mathrm{m})$ at the optimum condition of the considered process parameters. Furthermore, Samanta and Chakraborty (2011) attempted both single and weighted based 
multi-objective optimization using $\mathrm{ABC}$ for the considered EMM process and the result obtained for the performance parameters (i.e., MRR and ROC) using ABC for single objective optimization as 1.47 $(\mathrm{g} / \mathrm{min})$ and $0(\mu \mathrm{m})$ respectively. Similarly, the result obtained for weighted based multi-objective optimization using $\mathrm{ABC}$ giving equal weight to both the performance parameters (i.e., MRR and ROC) as $0.8550(\mathrm{~g} / \mathrm{min})$ and $0(\mu \mathrm{m})$ respectively. However, these non-dominated solutions obtained using NSGA-II is found comparable with the result of Samanta and Chakraborty (2011) and Munda and Bhattacharya (2006).

Table 5

Comparison of NSGA-II results for EMM process

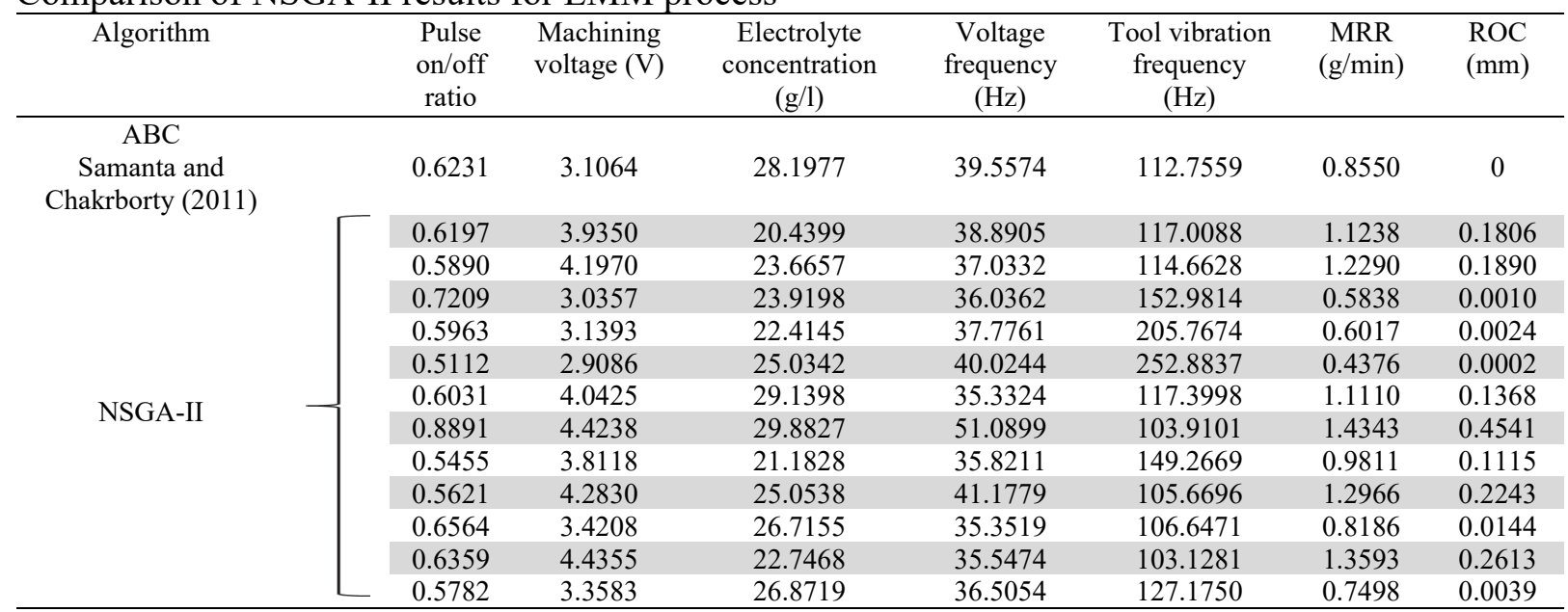

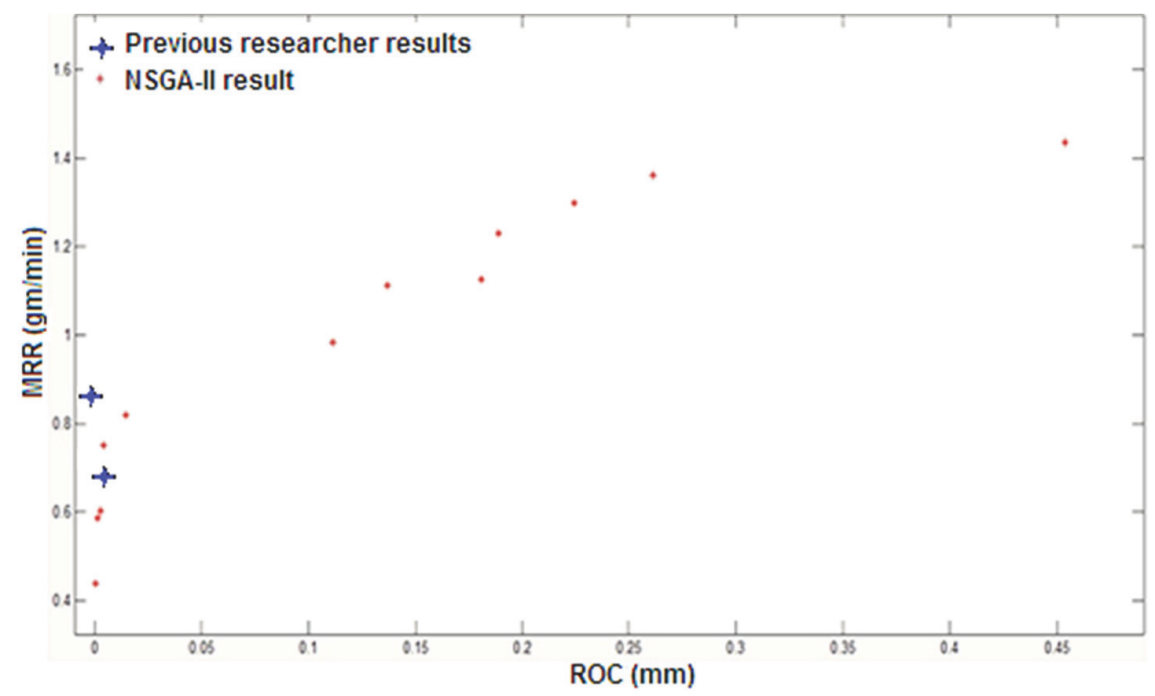

Fig. 2 Pareto optimal front and comparison of result for EMM process

\subsection{Example 3: USM process}

Lalchhuanvela et al. (2012) conducted experiments on an "AP-1000” Sonic- Mill, a 1000W ultrasonic machine (USM) having frequency of vibration $20 \mathrm{kHz}$. They considered work holding plate was made of mild steel specially fabricated with cavity size of $30 \times 30 \times 8 \mathrm{~mm}$ and a flat plate of $40 \times 40 \times 5 \mathrm{~mm}$ of alumina ceramic was used as the workpiece with boron carbide powder of different grain sizes mixed with water was used as an abrasive slurry. They have used tubular stainless steel of hexagonal shape $17 \mathrm{~mm}$ long and $8.7 \mathrm{~mm}$ hole diameter as a tool. Lalchhuanvela et al. (2012) considered four process parameters, i.e., grit size $(\mu \mathrm{m})$, slurry concentration $(\%)$, power rating $(\%)$, feed rate $(\mathrm{mm} / \mathrm{min})$ and slurry flow rate (lit/min), and two performance parameter $M R R(\mathrm{gm} / \mathrm{min})$ and $R a(\mu \mathrm{m})$ for the 
experimental work. These process parameters were set at five different levels. The actual values and coded values of different process parameters are given in Table 6.

\section{Table 6}

Process factors and their bounds for USM (Lalchhuanvela et al., 2012)

\begin{tabular}{lcccccc}
\hline \multicolumn{1}{c}{ Parameters } & Symbol & \multicolumn{3}{c}{ Levels } \\
\hline & & -2 & -1 & 0 & 1 & 2 \\
Grit size $(\mu \mathrm{m})$ & $x_{1}$ & 14 & 24 & 34 & 44 & 63 \\
Slurry concentration $(\%)$ & $x_{2}$ & 30 & 35 & 40 & 45 & 50 \\
Power rating $(\%)$ & $x_{3}$ & 40 & 45 & 50 & 55 & 60 \\
Feed rate $(\mathrm{mm} / \mathrm{min})$ & $x_{4}$ & 0.84 & 0.96 & 1.08 & 1.20 & 1.32 \\
Slurry flow rate $(\mathrm{lit} / \mathrm{min})$ & $x_{5}$ & 6 & 7 & 8 & 9 & 10 \\
\hline
\end{tabular}

Lalchhuanvela et al. (2012) used central composite second order half fraction rotatable design (CCRD) experimentation plan with 32 experimental runs. The mathematical predictive regression models are remodeled for the experimental results of Lalchhuanvela et al. (2012) with the use of MINITAB software using coded values of the considered process parameters as given in Eq. (12) and (13):

$$
\begin{aligned}
& M R R=0.034205+0.00264583 x_{1}-0.00347917 x_{2}-0.00139583 x_{3}-0.0001875 x_{4}+0.0008125 x_{5}+ \\
& 0.00151989 x_{1}^{2}-0.000542614 x_{2}^{2}+0.000363636 x_{3}^{2}-0.000605114 x_{4}^{2}-0.000292614 x_{5}^{2}- \\
& 0.00282813 x_{1} x_{2}-0.000546875 x_{1} x_{3}+0.000328125 x_{1} x_{4}+0.000328125 x_{1} x_{5}+0.000609375 x_{2} x_{3}- \\
& 0.000203125 x_{2} x_{4}-0.000328125 x_{2} x_{5}-0.000484375 x_{3} x_{4} \\
& R a=0.607727+0.026667 x_{1}-0.00958333 x_{2}-0.0070833 x_{3}-0.0037500 x_{4}+0.0133333 x_{5}+ \\
& 0.000994318 x_{1}^{2}-0.00443182 x_{2}^{2}+0.00224432 x_{3}^{2}-0.00838068 x_{4}^{2}-0.0080682 x_{5}^{2}- \\
& 0.00437500 x_{1} x_{2}-0.00906250 x_{1} x_{3}+0.00343750 x_{1} x_{4}+0.002500 x_{1} x_{5}+0.00406250 x_{2} x_{3}- \\
& 0.00343750 x_{2} x_{4}-0.0012500 x_{2} x_{5}-0.00437500 x_{3} x_{4}+0.00281250 x_{3} x_{5}-0.000937500 x_{4} x_{5}
\end{aligned}
$$

The aim of the present work is to maximize the objective "MRR" and to minimize the objective "Ra" for the considered USM machining process and these objectives are optimized simultaneously. The objective functions are given in Eq. (13) and (14) for $M R R$ and $R a$ respectively. Since the objectives are differing in nature, modification of the first objective $(M R R)$ is made as done in the considered example of EDM and EMM process. The objectives are given in Eq. (14). Four solutions are obtained at the end of the generations with computation time 53.18 seconds. The Pareto-optimal solution and comparison of the results with the results of Lalchhuanvela et al. (2012) are reported in Table 7. Fig. 3 shows the Pareto- optimal front and the previous researcher result based on steepest assent method used for solving the considered multi-objective problem.

Objective $1=-($ MRR $)$

Objective $2=\mathrm{Ra}$

Lalchhuanvela et al. (2012) considered multi-objective optimization and solution obtained for MRR and $\mathrm{Ra}$ as 0.0580 and 0.6159 respectively. The solutions obtained using NSGA-II are not biased to the domain of the USM process parameters, and these solutions are found comparable with the result (Lalchhuanvela et al., 2012). The result reported in Table 7 clearly shows the four non-dominated solutions in the considered USM process.

Table 7

Comparison of NSGA-II results for USM process

\begin{tabular}{cccccccc}
\hline Algorithm & $\begin{array}{c}\text { Grit size } \\
(\mu \mathrm{m})\end{array}$ & $\begin{array}{c}\text { Slurry } \\
\text { concentration } \\
(\%)\end{array}$ & $\begin{array}{c}\text { Power } \\
\text { rating }(\%)\end{array}$ & $\begin{array}{c}\text { Feed rate } \\
(\mathrm{mm} / \mathrm{min})\end{array}$ & $\begin{array}{c}\text { Slurry } \\
\text { flow rate } \\
(\text { lit/min })\end{array}$ & $\begin{array}{c}\text { MRR } \\
(\mathrm{g} / \mathrm{min})\end{array}$ & $\begin{array}{c}\text { Ra } \\
(\mu \mathrm{m})\end{array}$ \\
\hline $\begin{array}{c}\text { Steepest assent Lalchhuanvela et } \\
\text { al. (2012) }\end{array}$ & 55 & 50 & 40 & 1.01 & 10 & 0.0580 & 0.6159 \\
\hline & 59.7329 & 44.6665 & 49.3335 & 1.1599 & 8.1333 & 0.0396 & 0.5313 \\
NSGA-II & 53.2 & 50 & 40 & 1.0640 & 8.4000 & 0.0311 & 0.4898 \\
& 59.7329 & 36.6665 & 41.3335 & 1.1599 & 8.6666 & 0.0604 & 0.5450 \\
& 59.7329 & 46 & 42.667 & 0.9680 & 7.3334 & 0.0378 & 0.5287 \\
\hline
\end{tabular}




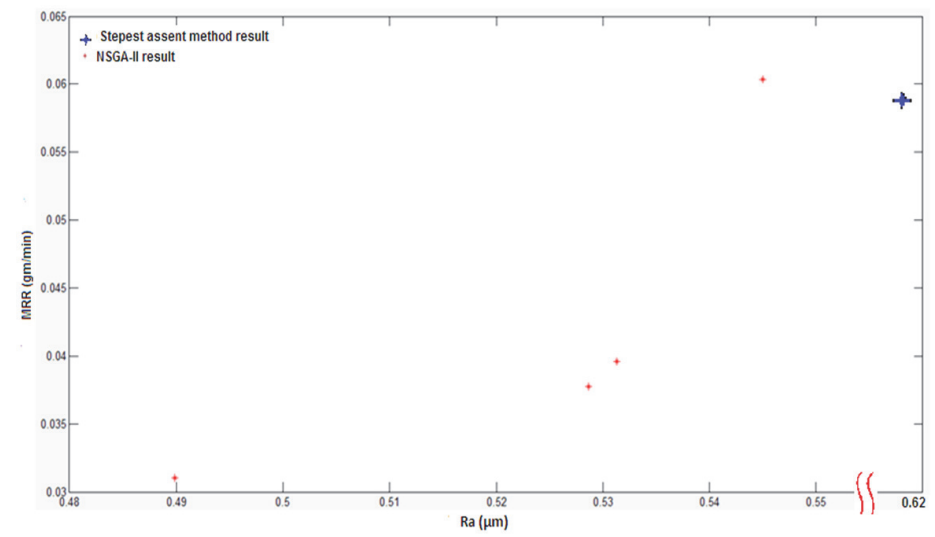

Fig. 3 Pareto optimal front and comparison of result for USM process

\subsection{Example 4: AWJM process}

Yue et al. (2014) have conducted experiments on cylindrical specimens, i.e., $96 \%$ alumina ceramic tube using the specially designed abrasive water jet machining (AWJM) turning setup. They have considered five principal machining parameters of AWJM process, including water pressure, jet feed speed, abrasive mass flow rate, surface speed and nozzle tilted angle are employed to investigate the influence of machining parameters on the $M R R$ and $R a$. The actual and coded values of considered parameters are shown in Table 8 .

\section{Table 8}

Process factors and their bounds of AWJM process (Yue et al., 2014)

\begin{tabular}{lcccc}
\hline \multicolumn{1}{c}{ Parameter } & Units & Level1 & Level2 & Level3 \\
\hline Water pressure & $\mathrm{MPa}$ & 190 & 250 & 310 \\
Jet feed speed & $\mathrm{mm} / \mathrm{s}$ & 0.05 & 0.15 & 0.25 \\
Abrasive mass flow rate & $\mathrm{g} / \mathrm{s}$ & 3.5 & 7.5 & 11.5 \\
Surface speed & $\mathrm{m} / \mathrm{s}$ & 1.5 & 5.5 & 9.5 \\
Nozzle tilted angle & $\circ$ & 45 & 75 & 105 \\
\hline
\end{tabular}

A face-centered central composite design plan was used and then RSM was employed to develop the regression Eq. for the performance parameters. The mathematical predictive regression models in coded form for performance parameters given in Yue et al. (2014) are presented in Eq. (15) and (16).

$$
\begin{aligned}
& M R R=3814.35+943.50 x_{1}-530.29 x_{2}+745.01 x_{3}+154.83 x_{4}-193.65 x_{5}+551.62 x_{1} x_{3}+ \\
& 284.87 x_{1} x_{5}-147.61 x_{2} x_{5}+225.723 x_{3} x_{4}+345 x_{2}^{2}-483.49 x_{3}^{2}-430 x_{4}^{2} \\
& R a=3.78+0.31 x_{1}+0.04 x_{2}-0.38 x_{3} 0.087 x_{4}+0.046 x_{5}-0.24 x_{1} x_{2}-0.067 x_{4} x_{5}-0.17 x_{2}^{2}+0.17 x_{3}^{2} \\
& +0.14 x_{5}^{2}
\end{aligned}
$$

\begin{tabular}{|c|c|c|c|c|c|c|c|}
\hline Algorithm & $\begin{array}{c}\text { Water } \\
\text { pressure } \\
(\text { Mpa })\end{array}$ & $\begin{array}{c}\text { Jet feed speed } \\
(\mathrm{m} / \mathrm{s})\end{array}$ & $\begin{array}{c}\text { Abrasive mass flow } \\
\text { rate }(\mathrm{g} / \mathrm{s})\end{array}$ & $\begin{array}{c}\text { Surface speed } \\
(\mathrm{m} / \mathrm{s})\end{array}$ & $\begin{array}{l}\text { Nozzle tilted } \\
\text { angle }\left({ }^{\circ}\right)\end{array}$ & $\begin{array}{c}M R R \\
\left(\mu m^{3} / \mu s\right)\end{array}$ & $\begin{array}{l}R a \\
(\mu m)\end{array}$ \\
\hline SAO & & & & & & & \\
\hline \multirow{4}{*}{$\begin{array}{l}\text { Yue et al. } \\
\text { (2014) }\end{array}$} & 310 & 0.25 & 11.5 & 6 & 71 & 5441.96 & 3.41 \\
\hline & 214.942 & 0.0837 & 10.59 & 4.7312 & 55.587 & 3894.717 & 3.2164 \\
\hline & 292.588 & 0.0571 & 9.304 & 7.4922 & 61.236 & 5643.681 & 3.9046 \\
\hline & 213.532 & 0.0696 & 8.2688 & 8.4961 & 45.942 & 4098.765 & 3.4661 \\
\hline \multirow[t]{4}{*}{ NSGA-II } & 273.7648 & 0.0861 & 9.5236 & 5.6098 & 81.2352 & 5041.66 & 3.7374 \\
\hline & 280.3528 & 0.0798 & 9.6804 & 8.9353 & 63.588 & 5149.501 & 3.8529 \\
\hline & 198.94 & 0.0524 & 10.2764 & 1.8136 & 101.0001 & 2911.567 & 3.0521 \\
\hline & 202.234 & 0.068 & 9.8688 & 4.1352 & 82.647 & 3516.614 & 3.0612 \\
\hline
\end{tabular}

\section{Table 9}

Comparison of NSGA-II results for AWJM process 
As the objectives are conflicting in nature and the objectives are modified as given in Eq. (17). Total seven solutions are obtained at the end of the generations with computation time 151.80 seconds. The Pareto-optimal solution obtained using NSGA-II and it's comparison with the result of Yue et al. (2014) is reported in Table 9. Fig. 4 shows the Pareto- optimal front for all non-dominated solutions. Yue et al. (2014) have applied sequential approximation optimization (SAO) method to obtain the optimum setting for the considered problem and they obtained MRR and Ra as $5441.96 \mu \mathrm{m}^{3} / \mu \mathrm{s}$ and $3.41 \mu \mathrm{m}$ respectively. However, the solutions obtained using NSGA are not biased to the domain of the process parameters, and these solutions are found comparable with the result of (Yue et al., 2014). The result reported in Table 9 clearly shows the seven non-dominated solutions in the considered AWJM process.

Objective $1=-(M R R)$

Objective 2=Ra

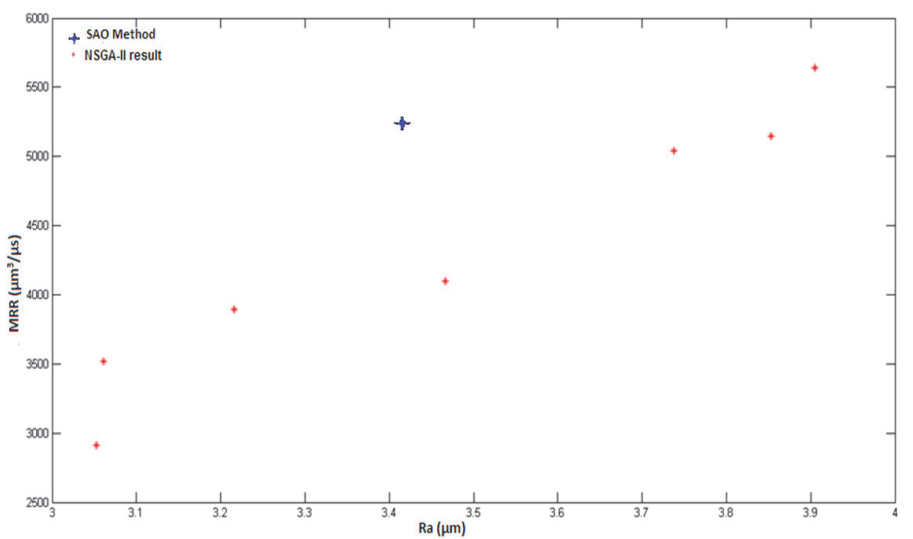

Fig. 4. Pareto optimal front and comparison of result for AWJM process

\section{Conclusions}

This paper investigates the four NTM processes, i.e., "EDM", "EMM", "USM" and "AWJM" to determine the set of alternative solutions using NSGA-II which can be utilized by the manufacturing industries to improve the performance of the processes. The results obtained using NSGA-II is compared with the result of the previous researcher in the considered case studies. In the case of the EDM process, a Pareto-optimal set of thirty solutions are obtained and the solutions obtained are not biased towards the bound values of the process parameters of the considered process. It leads to true optimal solutions using NSGA-II and it gives the flexibility to the manufacturers as a number of the alternative optimum set of parameters are available and they can use them according to their requirement. Similarly, the result obtained for other machining processes EMM, USM and AWJM process using NSGA-II is non-dominated with respect to all other solutions. Twelve, four and seven non-dominated solutions are reported for EMM, USM and AWJM processes. Using NSGA-II as the optimization tools, it is possible to determine alternative optimal settings for other NTM processes to have improved responses. It shows the applicability and effectiveness of NSGA-II to the optimization of various NTM processes.

\section{References}

Acharya, B.R., Mohanty, C.P. \& Mahapatra, S.S. (2013). Multi-objective optimization of electrochemical machining of hardened steel using NSGA-II. Procedia Engineering, 51, 554-560.

Asokan, P., Ravi Kumar, R., Jeyapaul, R. \& Santhi, M. (2008). Development of multi-objective optimization models for electrochemical machining process. International Journal of Advance Manufacturing Technology, 39 (1-2), 55-63. 
Bansal, K. \& Goyal, K. (2013). Investigation into the machining characteristics of composites using chemical assisted ultrasonic machining process. International Journal of Research in Mechanical Engineering Technology, 3(2), 78-84.

Bharti, P.S., Maheswari, S. \& Sharma, C. (2012). Multi-objective optimization of electric-discharge machining process using controlled elitist NSGA-II. Journal of Mechanical Science and Technology, 26, 1875-1883.

Chakravorty, R., Gauri, S. K. \& Chakraborty, S. (2013). Optimization of multiple responses of ultrasonic machining (USM) Process : A Comparative. International Journal of Industrial Engineering Computational, 4, 285-296.

Deb, K., Pratap, A., Agarwal, S. \& Meyarivan, T. (2002). A fast elist multi-objective genetic algorithm: NSGAII. IEEE Transaction of Evolutionary Computational, 6,182-197.

Dewangan, S., Gangopadhyay, S. \& Biswas, C.K. (2015). Multi-response optimization of surface integrity characteristics of EDM process using grey-fuzzy logic-based hybrid approach. Engineering Science and Technolology Internatinal Journal, 1, 1-8.

Gao, L., Huang, J. \& Li, X. (2013). An effective cellular particle swarm optimization for parameter optimization of a multi-pass milling process. Applied Soft Computing, 12, 3490-3499.

Goswami, D. \& Chakraborty, S. (2015). Parametric optimization of ultrasonic machining process using gravitational search and fireworks algorithms. Ain Shams Engineering Journal, 6 (1), 315-331.

Inamdar, S. V., Gupta, K. S. \& Saraf, D. N. (2004). Multi objective optimization of an industrial crude distillation unit using the elitist non-dominated sorting genetic algorithm. Chemical Engineering Research and Design, $82(5), 611-623$.

Jensen, M.T. (2003). Reducing the run-time complexity of multiobjective EAs: The NSGA-II and Other Algorithms. IEEE Transacactions of Evolutionary Computation, 7(5), 503-515.

Keskin, Y., Halkac1, H.S. \& Kizil, M. (2005). An experimental study for determination of the effects of machining parameters on surface roughness in electrical discharge machining (EDM). International Journal of Advance Manufacturing Technology, 28, 1118-1121.

Konak, A., Coit, D.W. \& Smith, A.E. (2006). Multi-objective optimization using genetic algorithms: A tutorial. Releability Engineering System and Safety, 91, 992-1007.

Kumar, J. \& Khamba, J. S. (2008). An experimental study on ultrasonic machining of pure titanium using designed experiments. Journal of Brazilian Society of Mechanical Science and Engineering, 3, 231-238.

Kumar, V. (2013). Optimization and modeling of process parameters involved in ultrasonic machining of glass using design of experiments and regression approach. American Journal of Material Engineering Technology, 1(1),13-18.

Kuriakose, S. \& Shunmugam, M.S. (2005). Multi-objective optimization of wire-electro discharge machining process by non-dominated sorting genetic algorithm. Journal of Material Processing Technology, 170, 133141.

Kuruc, M., Vopat, T. \& Peterka, J. (2015). Surface roughness of poly-crystalline cubic boron nitride after rotary ultrasonic machining. Procedia Engineering, 100, 877-884.

Lalchhuanvela, H., Doloi, B. \& Bhattacharyya, B. (2012). Enabling and understanding ultrasonic machining of engineering ceramics using parametric analysis. Material and Manufacturing Processes, 27(4), 443-448.

Lozano Torrubia, P., Axinte, D. \& Billingham, J. (2015). Stochastic modelling of abrasive waterjet footprints using finite element analysis. International Journal of Machine Tools and Manufacturer, 95, 39-51.

Mandal, D., Pal, S.K. \& Saha, P. (2007). Modeling of electrical discharge machining process using back propagation neural network and multi-objective optimization using non-dominated sorting genetic algorithmII. Journal of Material Processing Technology, 186, 154-162.

Marler, R.T. \& Arora, J.S. (2004). Survey of multi-objective optimization methods for engineering. Structure of Multidisciplinary Optimization, 26(6), 369-395.

Munda, J. \& Bhattacharyya, B. (2006). Investigation into electrochemical micromachining (EMM) through response surface methodology based approach. International Journal of Advance Manufacturing and Technology, 35, 821-832.

Muthuramalingam, T. \& Mohan, B. (2014). A review on influence of electrical process parameters in EDM process. Archives of Civil and Mechanical Engineering, 15(1), 1-8.

Pasupathy, T., Chandrasekharan, R. \& Suresh, R.K. (2006). A multi-objective genetic algorithm for scheduling in flow shops to minimize the make span and total flow time of jobs. International Journal of Advance Manufacturing Technology, 27, 804-815.

Popli, D. \& Singh, R.P. (2013). Machining process parameters of USM- A Review. International Journal of Emerging Research in Management Technology, 2(10), 46-50. 
Rajabi-Bahaabadi, M. Shariat-Mohaymany, A., Babaei, M. \& Ahn, C.W. (2015). Multi-objective path finding in stochastic time-dependent road networks using non-dominated sorting genetic algorithm. Expert Systems with Applications, 42(12), 5056-5064.

Rajurkar, K.P., Sundaram, M.M. \& Malshe, A.P. (2013). Review of electrochemical and electrodischarge machining. Procedia CIRP, 6,13-26.

Ramesh, S., Kannan, S. \& Baskar, S. (2012). Application of Modified NSGA-II Algorithm to Multi-Objective Reactive Power Planning. Applied Soft Computing Journal, 12 (2), 741-753.

Rout, S. K., Balaji, K., Choudhury, R., Sahoo, K. \& Sarangi, S. K. (2014). Multi-objective parametric optimization of inertance type pulse tube refrigerator using response surface methodology and non-dominated sorting genetic algorithm. Cryogenics, 62, 71-83.

Samanta, S. \& Chakraborty, S. (2011). Parametric optimization of some non-traditional machining processes using artificial bee colony algorithm. Engineering Applications of Artificial Intelligence, 24, 946-957.

Schwartzentruber, J. \& Papini, M. (2015). Abrasive waterjet micro-piercing of borosilicate glass. Journal of Material Processing Technology, 219, 143-154.

Senthilkumar, C., Ganesan, G. \& Karthikeyan, R. (2011). Parametric optimization of electrochemical machining of Al/15\% SiCp composites using NSGA-II. Transactions of Nonferrous Metals Society of China, 21, 22942300 .

Singh, N. \& Gianender (2012). USM for hard or brittle material and effect of process parameters on MRR or surface roughness : A Review. International Journal of Applied Engineering Research, 7 (11), 1-6.

Srinivas, N. \& Deb, K. (1994). Multi-objective Optimization using non-dominated sorting in genetic algorithm. Evolutionary Computational, 2, 221-248.

Subramanian, G. \& Thiagarajan, S. (2014). Optimization of machining parameters for EDM operations based on central composite design and desirability approach. Journal of Mechanical Science and Technology, 28(3), $1045-1053$.

Taboada, H. A., Fatema, B., David, W. C. \& Naruemon, W. (2007). Practical Solutions for Multi-Objective Optimization: An Application to System Reliability Design Problems. Reliability Engineering and System Safety, 92(3), 314-322.

Talla, G., Sahoo, D.K., Gangopadhyay, S. \& Biswas, C.K. (2015). Modeling and multi-Objective optimization of powder mixed electric discharge machining process of aluminum/alumina metal matrix composite, Engineering Science and Technolology International Journal, 1, 1-5.

Teimouri, R. \& Baseri, H. (2014). Optimization of magnetic field assisted EDM using the continuous ACO algorithm, Applied Soft Computing, 14, 381-389.

Tzeng, C.J. \& Chen, Y.R. (2013). Optimization of electric discharge machining process using the response surface methodology and genetic algorithm approach. International Journal of Precesion Engineering and Manufacturer, 14, 709-717.

Wang, W., Radu, Z. \& Hugues, R. (2005). Applying Multi-Objective Genetic Algorithms in Green Building Design Optimization, Building and Environment, 40 (11), 1512-1525.

Wenjun, G., Jianming, W. \& Na, G. (2011). Numerical simulation for abrasive water jet machining based on ALE algorithm. International Journal of Advance Manufacturing Technology, 53, 247-253.

Wong, J. Y., Q. Sharma, S. \& Rangaiah, G.P. (2016). Design of Shell-and-Tube Heat Exchangers for Multiple Objectives Using Elitist Non-Dominated Sorting Genetic Algorithm with Termination Criteria. Applied Thermal Engineering, 93, 888-899.

Yang, M.D., Chen, Y.P., Lin, Y.H., Ho, Y.F. \& Lin, J.Y. (2016). Multiobjective Optimization Using Nondominated Sorting Genetic Algorithm-II for Allocation of Energy Conservation and Renewable Energy Facilities in a Campus. Energy and Buildings, 122, 120-130.

Yue, Z., Huang, C., Zhu, H., Wang. J., Yao, P. \& Liu, Z.W. (2014). Optimization of machining parameters in the abrasive water-jet turning of alumina ceramic based on the response surface methodology, International Journal of Advance Manufacturing Technology, 71, 107-114.

Yusoff, Y., Ngadiman, M. S. \& Zain, A.M. (2011). Overview of NSGA-II for optimizing machining process parameters, Procedia Engineering, 15, 3978-3983.

Yuvaraj, N. \& Kumar, M.P. (2014). Multi response optimization of abrasive water jet cutting process parameters using TOPSIS approach. Material and Manufacturing Processes, 30(7), 37-41. 


\section{APPENDIX}

\section{Parametric analysis for selecting control parameters}

\begin{tabular}{|c|c|c|c|c|c|c|c|c|}
\hline \multicolumn{9}{|c|}{ (a) Effect of iterations on the number of solutions } \\
\hline No. & Number of iteration & population & Mutation & Crossover rate & Trial 1 & Trial 2 & Trial 3 & Average \\
\hline 1 & 100 & 10 & 0.3 & 0.5 & 13 & 15 & 11 & 13 \\
\hline 2 & 200 & 10 & 0.3 & 0.5 & 9 & 13 & 14 & 12 \\
\hline 3 & 300 & 10 & 0.3 & 0.5 & 9 & 13 & 19 & 13.6667 \\
\hline 4 & 400 & 10 & 0.3 & 0.5 & 13 & 10 & 15 & 12.6667 \\
\hline 5 & 500 & 10 & 0.3 & 0.5 & 19 & 12 & 6 & 12.3333 \\
\hline 6 & 600 & 10 & 0.3 & 0.5 & 12 & 12 & 10 & 11.3333 \\
\hline 7 & 700 & 10 & 0.3 & 0.5 & 12 & 8 & 7 & 9 \\
\hline 8 & 800 & 10 & 0.3 & 0.5 & 8 & 9 & 14 & 10.3333 \\
\hline 9 & 900 & 10 & 0.3 & 0.5 & 12 & 11 & 11 & 11.3333 \\
\hline 10 & 1000 & 10 & 0.3 & 0.5 & 10 & 11 & 12 & 11 \\
\hline \multicolumn{9}{|c|}{ (b) Effect of population on the number of solutions } \\
\hline No. & Number of iteration & population & Mutation & Crossover rate & Trial 1 & Trial 2 & Trial 3 & Average \\
\hline 1 & 300 & 10 & 0.3 & 0.5 & 9 & 13 & 19 & 13.6667 \\
\hline 2 & 300 & 20 & 0.3 & 0.5 & 10 & 17 & 17 & 14.6667 \\
\hline 3 & 300 & 30 & 0.3 & 0.5 & 19 & 19 & 11 & 16.3333 \\
\hline 4 & 300 & 40 & 0.3 & 0.5 & 23 & 18 & 16 & 19 \\
\hline 5 & 300 & 50 & 0.3 & 0.5 & 20 & 28 & 23 & 23.6667 \\
\hline 6 & 300 & 60 & 0.3 & 0.5 & 20 & 28 & 27 & 25 \\
\hline 7 & 300 & 70 & 0.3 & 0.5 & 30 & 28 & 24 & 27.3333 \\
\hline 8 & 300 & 80 & 0.3 & 0.5 & 30 & 25 & 29 & 28 \\
\hline 9 & 300 & 90 & 0.3 & 0.5 & 30 & 25 & 30 & 28.3333 \\
\hline 10 & 300 & 100 & 0.3 & 0.5 & 29 & 30 & 30 & 29.6667 \\
\hline \multicolumn{9}{|c|}{ (c) Effect of mutation rate on the number of solutions } \\
\hline No. & Number of iteration & population & Mutation & Crossover rate & Trial 1 & Trial 2 & Trial 3 & Average \\
\hline$\overline{1}$ & 300 & 100 & 0.1 & 0.5 & 12 & 14 & 16 & 14 \\
\hline 2 & 300 & 100 & 0.2 & 0.5 & 19 & 24 & 25 & 22.66667 \\
\hline 3 & 300 & 100 & 0.3 & 0.5 & 24 & 27 & 30 & 27 \\
\hline 4 & 300 & 100 & 0.4 & 0.5 & 27 & 24 & 22 & 24.33333 \\
\hline 5 & 300 & 100 & 0.5 & 0.5 & 25 & 24 & 23 & 24 \\
\hline 6 & 300 & 100 & 0.6 & 0.5 & 27 & 19 & 23 & 23 \\
\hline 7 & 300 & 100 & 0.7 & 0.5 & 23 & 22 & 25 & 23.33333 \\
\hline 8 & 300 & 100 & 0.8 & 0.5 & 24 & 21 & 21 & 22 \\
\hline 9 & 300 & 100 & 0.9 & 0.5 & 27 & 20 & 17 & 21.33333 \\
\hline 10 & 300 & 100 & 1 & 0.5 & 22 & 26 & 22 & 23.33333 \\
\hline \multicolumn{9}{|c|}{ (d) Effect of crossover rate on the number of solutions } \\
\hline No. & Number of iteration & population & Mutation & Crossover rate & Trial 1 & Trial 2 & Trial 3 & Average \\
\hline 1 & 300 & 100 & 0.3 & 0.1 & 21 & 22 & 17 & 20 \\
\hline 2 & 300 & 100 & 0.3 & 0.2 & 14 & 28 & 25 & 22.3333 \\
\hline 3 & 300 & 100 & 0.3 & 0.3 & 20 & 26 & 24 & 23.3333 \\
\hline 4 & 300 & 100 & 0.3 & 0.4 & 25 & 30 & 22 & 25.6667 \\
\hline 5 & 300 & 100 & 0.3 & 0.5 & 24 & 27 & 30 & 27 \\
\hline 6 & 300 & 100 & 0.3 & 0.6 & 16 & 23 & 23 & 20.6667 \\
\hline 7 & 300 & 100 & 0.3 & 0.7 & 24 & 17 & 23 & 21.3333 \\
\hline 8 & 300 & 100 & 0.3 & 0.8 & 22 & 22 & 21 & 21.6667 \\
\hline 9 & 300 & 100 & 0.3 & 0.9 & 21 & 28 & 22 & 23.6667 \\
\hline 10 & 300 & 100 & 0.3 & 1 & 22 & 21 & 20 & 21 \\
\hline
\end{tabular}


(C) 2020 by the authors; licensee Growing Science, Canada. This is an open access article distributed under the terms and conditions of the Creative Commons Attribution (CC-BY) license (http://creativecommons.org/licenses/by/4.0/). 